\title{
Efektivitas promosi kesehatan menggunakan metode index card match dan metode visual auditory kinesthetic terhadap pengetahuan dan keterampilan cuci tangan pada disabilitas intelektual ringan
}

\author{
Umi Rofiatun Rojabtiyah *, Pramono Giri K, Erna Erawati, Sunarko \\ Program Studi Keperawatan Magelang, Poltekkes Kemenkes Semarang. Jl. Perintis Kemerdekaan, \\ Magelang, 56115, Indonesia. \\ * Corresponding Author. E-mail: rofiatunrojabtiyah@gmail.com
}

\begin{abstract}
Abstrak: Perilaku mencuci tangan belum menjadi kebiasaan penyandang disabilitas intelektual ringan. Diperlukan pemberian promosi kesehatan yang kreatif dan menarik agar pesan yang disampaikan dapat dengan mudah dipahami, seperti menggungakan metode Index Card Match dan Visual Auditory Kinesthetic. Tujuan dari penelitian ini adalah untuk mengetahui perbedaan efektivitas pemberian promosi kesehatan menggunakan metode Index Card Match dan Visual Auditory Kinesthetic terhadap peingkatan pengetahuan dan keterampilan cuci tangan penyandang disabilitas intelektual ringan. Penelitian ini menggunakan rancangan penelitian quasi experimental two group pretest posttest design dengan menggunakan alat ukur berupa soal pengukuran pengetahuan dan lembar pengukuran keterampilan cuci tangan. Kemudian data dianalisis menggunakan uji wilcoxon untuk mengetahui perbedaan pretest-postest dan uji mann-whitney untuk mengetahui perbedaan kelompok Index Card Match dan Visual Auditory Kinesthetic. Tidak terdapat perbedaan yang signifikan pada peningkatan pengetahuan antara kedua kelompok perlakuan dengan p value 0,311 ( $>>0,05)$. Dan terdapat perbedaan yang signifikan antara kedua kelompok perlakuan, yaitu pada kelompok promosi kesehatan metode ICM terbukti secara signifikan memiliki pengaruh yang lebih besar dengan $\mathrm{p}$ value $0,000(\mathrm{p}<0,05)$.
\end{abstract}

Kata Kunci: index card match, visual auditory kinesthetic, cuci tangan, disabilitas intelektual ringan

\section{Effectiveness of health promotion using index card match and visual auditory kinesthetic on washing hands knowledge and skill among children with mild intellectual disability}

\begin{abstract}
Hand washing behavior has not become a habit for people with mild intellectual disabilities. Necessary provision of health promotion creative and interesting so that the message can be easily understood, such as uses method Index Card Match and Visual Auditory Kinesthetic. The purpose of this research is to compare the differences of the effectiveness of the giving health promotion by using the Index Card Match and Visual Auditory Kinesthetic methods toward the increases of the knowledge and skills of hand washing of people with mild intellectual disabilities. This research used a quasi-experimental two-group pretest posttest design with measuring instruments in the form of knowledge and hand washing skill questionnaire. Then, the data were analyzed by using the Wilcoxon test to determine the difference in pre-test and post-test and MannWhitney test to determine the differences in the Index Card Match and Visual Auditory Kinesthetic groups. There were no significant differences in the increase in knowledge between the two treatment groups with $p$ value 0.311 ( $>>0.05)$. There were significant differences between the two experimental groups, such as in the health promotion group the ICM method proved has significantly greater influence with p value $0,000(\mathrm{p}<0.05)$.
\end{abstract}

Keywords: index card match, visual auditory kinesthetic, hand washing, mild intellectual disability

\section{PENDAHULUAN}

Salah satu upaya menjaga kesehatan individu hingga masyarakat yaitu dengan menerapkan Perilaku Hidup Bersih dan Sehat (PHBS) (Notoatmodjo, 2014). Program PHBS diharapkan mampu meningkatkan derajat kesehatan seluruh lapisan masyarakat Indonesia termasuk penyandang disabilitas, sesuai dengan UU No 36 Tahun 2009 yang menyatakan bahwa setiap orang memiliki hak mendapatkan upaya pemeliharaan kesehatan agar mampu hidup sehat dan produktif secara sosial, ekonomi dan bermartabat. 
Dari hasil SUSENAS 2012 didapatkan 2,45\% penduduk Indonesia adalah penyandang disabilitas yang pada umumnya belum mendapatkan pelayanan kesehatan sebagaimana mestinya, salah satunya adalah disabilitas intelektual (Kemenkes, 2014).Disabilitas intelektual adalah istilah resmi yang digunakan di Indonesia untuk menyebut keadaan dimana fungsi pikir mengalami gangguan karena tingkat kecerdasan yang dibawah rata-rata.Ada beberapa klasifikasi disabilitas intelektual salah satunya adalah disabilitas intelektual ringan (mild) dengan IQ antara 50-70. Selain memiliki IQ dibawah rata-rata, penyandang disabilitas intelektual ringan memiliki karakteristik berupa ketidak mampuan merawat diri sendiri. Hal itu mengakibatkan kurangnya pengetahuan dan kemampuan penyandang disabilitas intelektual dalam CTPS.

Salah satu lembaga yang yang menjadi rujukan di Indonesia dalam rehabilitasi pada penyandang disabilitas intelektual adalah Balai Besar Rehabilitasi Sosial Penyandang Disabilitas Intelektual (BBRSPDI) "Kartini” Temanggung.Hasil wawancara pada guru pendamping mengatakan hampir semuanya belum bisa melakukan mencuci tangan dengan baik dan benar. Penyuluhan kesehatan sering dilakukan oleh tim perawat kesehatan menggunakan metode ceramah, tanya jawab dan demonstrasi, namun dibutuhkan pengulangan penyuluhan dan latihan cuci tangan untuk meningkatkan pengetahuan dan keterampilannya.Untuk mengatasi masalah tersebut, diperlukan metode yang tepat dalam sosialisasi CTPS dengan metode promosi kesehatan yang kreatif agar kegiatan promosi menjadi menarik sehingga materi yang disampaikan dapat mudah diingat dan membekas dalam ingatanpenyandang disabilitas intelektual ringan yang memiliki kelemahan fokus konsentrasi dan mengingat.Ada beberapa kreatifitas yang dapat digunakan dalam promosi kesehatan seperti Index Card Match (ICM) dan Visual Auditory Kinesthetic (VAK).

Index Card Match (ICM) adalah metode permainan mencocokkan kartu pertanyaan dan jawaban yang dilakukan secara berpasangan (Silberman, 2013). Kelebihan pembelajaran menggunakan Index Card Match ini adalah belajar dengan bermain sehingga dapat menarik minat siswa untuk terlibat aktif dalam pembelajaran dan dapat melatih siswa untuk bisa belajar mandiri karena konsep belajar yang menggunakan cara bermain (Fauzia, 2018). Metode lain yang dapat digunakan adalah Visual Auditory Kinesthetic (VAK) yaitu gaya belajar multi-sensorik yang melibatkan ketiga unsur gaya belajar, yaitu penglihatan, pendengaran, dan gerakan (Huda pada Nurellah, Panjaitan, \& Maulana, 2016).Kelebihan dari Visual Auditory Kinesthetic adalah metode ini bisa menjangkau setiap gaya belajar siswa sehingga memudahkan setiap siswa untuk memahami sesuatu (Alditia, Gusrayani, \& Panjaitan, 2016).

Berdasarkan beberapa paparan diatas peneliti tertarik untuk mengetahui perbedaan efektivitas pemberian promosi kesehatan menggunakan metode index card match dan visual auditory kinestheticterhadap pengetahuan dan keterampilan cuci tangan disabilitas intelektual ringan

\section{METODE}

Penelitian ini menggunakan jenis penelitian Quasi Experimental Two Group Pretest-Posttest Design yang dilakukan di BBRSPDI “Kartini” Temanggung pada bulan Februari-April 2019. Populasi pada penelitian ini adalah penyandang disabilitas intelektual ringan (debil) yang sudah menjadi penerima manfaat di BBRSPDI "Kartini” Temanggung kurang dari dua tahun. Teknik sampling yang digunakan adalah purposive sampling dengan kriteria inklusi dan eksklusi, sehingga mendapatkan sample sebanyak 40 penyandang disabilitas intelektual ringan (debil).

Pengumpulan data menggunakan instrumen pengukuran pengetahuan cuci tangan kuesioner multiple choice yang diadaptasi dari penelitian Wiratama (2017) yang telah diuji validitas dan reliabilitasnya pada tanggal 2 Februari 2019 pada 30 penyandang disabilitas yang memiliki karakteristik yang sama di SLB C Rindang Kasih dan SLB N Temanggung yang tidak digunakan sebagai populasi penelitian dan pengukuran keterampilan cuci tangan menggunakan alat ukur yang diadaptasi dari pedoman cuci tangan 6 langkah menurut WHO dalam bentuk checklist. Data akan dibandingkan tingkat pengetahuan dan keterampilan sebelum dan sesudah diberikan intervensi menggunakan uji Wilcoxon. Sedangkan untuk membandingkan hasil antara variabel pengetahuan dan keterampilan antara dua kelompok menggunakan uji Mann Whitney.

\section{HASIL DAN PEMBAHASAN}

Responden pada penelitian ini berjumlah 40 penyandang disabilitas intelektual ringan (debil) dengan rentang usia 15-35 dengan rata-rata umur responden adalah 22,02 tahun atau dalam kategori 
remaja akhir. Tidak ada pengaruh antara umur dan jenis kelamin terhadap kemampuan pengetahuan dan keterampilan mencuci tangan dengan baik dan benar, karena tidak ada pengelompokan kelas berdasarkan umur dan jenis kelamin tetapi berdasarkan tingkat kecerdasan. Sedangkan untuk tingkat kecerdasan sejalan dengan penelitian oleh Ahmad (2018) yang menyatakan bahwa tingkat kecerdasan lebih berpengaruh pada proses pembelajaran. Distribusi frekuensi karakteristik responden terlihat pada tabel 1.

Pengukuran data dilakukan dua kali yaitu sebelum dan sesudah diberikan intervensi. Hasil perhitungan rata-rata nilai pengukuran pengetahuan terlihat pada tabel 2 dan pengukuran keterampilan terlihat pada tabel 3.

Hasil analisa data perbedaan nilai rata-rata sebelum dan sesudah diberikan intervensi pada pengukuran pengetahuan terlihat pada tabel 4 dan pada pengukuran keterampilan terlihat pada tabel 5 . Sedangkan perbedaan efektivitas antara dua kelompok perlakuan pada pengukuran pengetahuan terlihat pada tabel 6 dan pada pengukuran keterampilan terlihat pada tabel 7 .

Tabel 1 Karakteristik Responden

\begin{tabular}{lrr}
\hline \multicolumn{1}{c}{ Variabel } & Frekuensi (f) & Persentase (\%) \\
\hline Jenis Kelamin & & \\
- Laki-laki & 32 & 70 \\
- Perempuan & 8 & 30 \\
Total & $\mathbf{4 0}$ & $\mathbf{1 0 0}$ \\
\hline Umur & & \\
- Remaja awal & 4 & 10 \\
- Remaja akhir & 30 & 75 \\
- Dewasa awal & 6 & 15 \\
Total & $\mathbf{4 0}$ & $\mathbf{1 0 0}$ \\
\hline Tipe Kecerdasan & & \\
- Debil & 40 & 100 \\
- Imbisil & 0 & 0 \\
Total & $\mathbf{4 0}$ & $\mathbf{1 0 0}$ \\
\hline
\end{tabular}

Tabel 2 Hasil Pengukuran Tingkat Pengetahuan Cuci Tangan

\begin{tabular}{ccc}
\hline \multirow{2}{*}{ Kelompok } & \multicolumn{2}{c}{ Mean } \\
\cline { 2 - 3 } & Pre & Post \\
\hline ICM & 7.25 & 10.55 \\
\hline VAK & 6.00 & 8.80 \\
\hline
\end{tabular}

Tabel 3 Hasil Pengukuran Keterampilan Cuci Tangan

\begin{tabular}{lrr}
\hline \multirow{2}{*}{ Kelompok } & \multicolumn{2}{c}{ Mean } \\
\cline { 2 - 3 } & Pre & \multicolumn{1}{c}{ Post } \\
\hline ICM & 2.10 & 5.80 \\
\hline VAK & 2.25 & 4.80 \\
\hline
\end{tabular}

Tabel 4 Perbedaan Pengetahuan Cuci Tangan Sebelum dan Sesudah Dilakukan Intervensi

\begin{tabular}{lrrr}
\hline \multirow{2}{*}{ Kelompok } & \multicolumn{1}{c}{ Pre } & \multicolumn{1}{c}{ Post } & P \\
\cline { 2 - 3 } & Median (min-maks) & Median (min-maks) & \\
\hline ICM & $8.50(2-11)$ & $10.50(6-14)$ & .000 \\
\hline VAK & $6(4-10)$ & $9.00(5-14)$ & .000 \\
\hline
\end{tabular}

Tabel 5 Perbedaan Keterampilan Cuci Tangan Sebelum dan Sesudah Dilakukan Intervensi

\begin{tabular}{lrrr}
\hline \multirow{2}{*}{ Kelompok } & \multicolumn{1}{c}{ Pre } & \multicolumn{1}{c}{ Post } & P \\
\cline { 2 - 3 } & Median (min-maks) & Median (min-maks) & \\
\hline ICM & $2.00(2-3)$ & $6.00(5-6)$ & .000 \\
\hline VAK & $2.00(2-3)$ & $5.00(3-6)$ & .000 \\
\hline
\end{tabular}


J PK (J urnal Pendidikan Khusus), 15 (2), 2019 - 71

Umi Rofiatun Rojabtiyah, Pramono Giri K, Erna Erawati, Sunarko

\begin{tabular}{ccc} 
Tabel 6 Perbedaan & Pengetahuan Cuci Tangan Kelompok ICM dan VAK \\
\hline Kelompok & Median (Minimum-Maksimum) & P \\
\hline ICM & $3.50(0.00-6.00)$ & $0.331-$ \\
VAK & $3.00(0.00-5.00)$ & 0.355 \\
\hline
\end{tabular}

Tabel 7 Perbedaan Keterampilan Cuci Tangan Kelompok ICM dan VAK

\begin{tabular}{ccc}
\hline Kelompok & Median (Minimum-Maksimum) & P \\
\hline ICM & $4.00(3.00-4.00)$ & $0.000-$ \\
VAK & $3.00(0.00-4.00)$ & 0.000 \\
\hline
\end{tabular}

Penelitian ini untuk mengetahui perbedaan tingkat pengetahuan dan keterampilan sebelum dan sesudah diberikan intervensi pada kelompok ICM dan VAK, data diolah menggunakan uji wilcoxon. Hasil penelitian ini menyebutkan bahwa terdapat perbedaan yang signifikan pada pengetahuan dan keterampilan sebelum dan sesudah diberikan intervensi promosi kesehatan menggunakan metode ICM maupun VAK dengan p value $0,000(\mathrm{p}<0,05)$. Dengan menggunakan metode ICM maupun VAK, terbukti dapat meningkatkan pengetahuan dan keterampilan cuci tangan pada penyandang disabilitas intelektual ringan. Hal ini dikarenakan metode ICM adalah metode pembelajaran yang dikemas dengan konsep bermain. Dengan konsep bermain mencocokkan kartu indeks selain menghibur, metode ICM ini dapat mendidik dan melatih keterampilan responden dalam menerapkan cuci tangan dengan baik dan benar. Penelitian sejenis yang menggunakan konsep bermain adalah penelitian oleh Ahmad (2018) yang menggunakan metode bermain puzzle untuk media pembelajaran pada penyandang disabilitas intelektual, yang menyimpulkan bahwa media puzzle memberikan pengaruh terhadap cuci kemampuan tangan penyandang disabilitas intelektual. Metode pembelajaran VAK (Visual, Auditori, Kinestetik) dapat mempermudah guru dan siswa dalam proses belajar mengajar, karena menggunakan tiga modalitas belajar sehingga guru dapat menjangkau tiap siswa yang memiliki gaya belajar berbeda-beda dan siswa mendapatkan hasil yang optimal. Hal ini sejalan dengan penelitian yang hampir serupa yaitu penelitian oleh Sholichah (2018) yang menggunakan metode modeling (contoh langsung) sebagai metode pembelajaran pada disabilitas intelektual, Sholichah menyimpulkan bahwa pembelajaran cukup berhasil dilihat dari adanya perubahan pada sikap dan perilaku responden dari yang sebelumya sering bergantung pada orang lain, menjadi mampu mengontrol diri sendiri meski terkadang masih harus selalu diawasi dan selalu dibimbing.

Untuk mengetahui perbedaan dua kelompok intervensi data diolah menggungakan uji Mann Whitney. Tidak ada perbedaan signifikan pada perubahan tingkat pengetahuan antara kelompok ICM dan VAK dengan p value $>0,05$, secara statistik tidak ada perbedaan bermakna pada variabel pengetahuan antara metode ICM dan VAK. Hal ini dikarenakan pada kedua metode sama-sama memiliki kelebihan yaitu menuntut audien terlibat aktif dalam proses pembelajaran. Hal ini sejalan dengan penelitian oleh Eprilia, Fatimah, \& Koryati, (2018) yang menyatakan bahwa melalui strategi pembelajaran Index Card Match peserta didik akan mengamati, memikirkan, memahami, bekerja sama dan mengingat situasi tertentu, peserta didik lebih menyakini apa yang diamati dan menemukan banyak cara untuk mengingat suatu hal tertentu dan menyelesaikan persoalan yang ada. Pernyataan lain yang mendukung adalah pembelajaran VAK ini bertujuan untuk mengoptimalkan ketiga modalitas belajar tersebut untuk menjadikan siswa merasa nyaman, sehingga menuntut siswa ikut aktif dalam pelajaran dan siswa dapat mudah memahami materi yang disampaikan (Shoimin pada Nurellah, Panjaitan, \& Maulana, 2016).

Namun secara perhitungan rata-rata ada perbedaan yang signifikan antara kelompok ICM dan VAK yaitu metode ICM lebih memberikan pengaruh yang lebih tinggi dalam peningkatan pengetahuan dibanding kelompok VAK, dengan selisih pretest dan posttest pada kelompok ICM lebih besar dibanding selisih pretest dan posttest pada kelompok VAK. Hal ini dikarenakan proses belajar ICM yang dikemas dengan bermain membuat responden antusias untuk mengikuti proses belajar. Seperti yang dikemukanan oleh Fauzia (2018) bahwa pembelajaran menggunakan metode Index Card Match menjadi sangat menyenangkan dan siswa menjadi antusias dalam mengikuti proses pembelajaran dengan menggunakan metode pembelajaran yang dikemas dengan permainan memasangkan kartu yang juga berfungsi untuk memantapkan materi yang telah dipelajari. Selain itu, Soraya dalam (Ahmad, 2018) menyatakan bahwa anak-anak biasanya menyukai alat permainan dengan bentuk yang sederhana dan tidak rumit yang disertai dengan warna dan bentuk yang menarik. 
Pada tingkat kemampuan keterampilan mencuci tangan terdapat perbedaan yang signifikan antara kelompok ICM dan VAK dengan p value 0,000 $(\mathrm{p}<0,05)$ yang artinya ada perbedaan yang signifikan antara ICM dengan VAK sebagai metode penyampaian pesan yaitu metode ICM memberikan pengaruh yang lebih tinggi dalam peningkatan keterampilan cuci tangan responden. Hal ini dikarenakan penggunaan media film meskipun belum memaksimalkan ketiga gaya belajar sudah beberapa kali dilakukan di BBRSPDI "Kartini" Temanggung dalam kegiatan bimbingan sehingga belajar menggunakan bantuan alat atau media film bukanlah hal baru bagi responden. Sedangkan metode ICM belum pernah dilakukan pada proses pembelajaran terlebih dalam menyampaikan promosi kesehatan yang dalam kesempatan ini adalah cuci tangan, sehingga responden menjadi tertarik dan turut aktif dalam proses pembelajaran sehingga metode ICM dapat meningkatkan hasil belajar responden. Hal ini sesuai dengan penelitian oleh Sarinarulita, Nawawi, Ibrahim (2014) yang menunjukkan bahwa penerapan model pembelajaran Index Card Match dapat meningkatkan keaktifan dan hasil belajar siswa. Selain itu penggunaan alat bantu atau media kartu yang termasuk kategori benda tiruan yang dipakai dalam metode index card match memiliki intensitas yang lebih tinggi dibanding alat bantu film dalam metode visual auditory kinesthetic dalam menyampaikan pengetahauan Dale pada (Notoatmodjo, 2014).

\section{SIMPULAN}

Hasil penelitian didapatkan bahwa secara perhitungan rata-rata pembelajaran menggunakan metode ICM lebih efektif dibanding VAK, dan pada peningkatan keterampilan terdapat perbedaan yang signifikan antara kedua kelompok perlakuan ( $\mathrm{p}$ value $<0,05$ ), yaitu pada kelompok promosi kesehatan metode ICM terbukti secara signifikan memiliki pengaruh yang lebih besar.

Promosi kesehatan metode ICM terbukti lebih efektif dalam menyampaikan materi cuci tangan sehingga dapat dijadikan suatu media pembelajaran yang kreatif dalam penyampaian kepada penyandang disabilitas intelektual ringan.

\section{DAFTAR PUSTAKA}

Kemenkes. (2014). Penyandang Disabilitas Pada Anak. Available at : http://www.depkes.go.id/download.php?file=download/pusdatin/infodatin/infodatin disabilitas. pdf [Accessed January, 4 2019]

Notoatmodjo, S. (2014). Promosi Kesehatan dan Perilaku Kesehatan. Jakarta: rineka cipta

Fauzia, AN. (2018). Keefektifan Penggunaan Metode "Index Card Match" Dalam Pembelajaran Kosakata Bahasa Mandarin Kelas X Sma Hang Tuah 2 Sidoarjo. Available at : https://jurnalmahasiswa.unesa.ac.id/index.php/manadarin/article/view/23572 [Accessed January, 4 2019]

Silberman. (2013). Active Learning : 101 Cara Belajar Peserta didik Aktif. Bandung : Nuansa Cendikia.

Alditia, AYT, Gusrayani, D, Panjaitan, RL. (2016). Pengaruh Model Visual, Auditory, dan Kinesthetic (Vak) Terhadap Hasil Belajar Siswa pada Materi Sifat-Sifat Cahaya. Available at : http://ejournal.upi.edu/index.php/penailmiah/article/view/3041 [Accessed January, 4 2019]

Nurellah, A., Panjaitan, R. L., \& Maulana. (2016). Penerapan Model Pembelajaran Visual , Auditorial , Dan Kinestetik Untuk Meningkatkan Hasil Belajar Siswa Sekolah Dasar. Available at : http://ejournal.upi.edu/index.php/penailmiah/article/download/3053/pdf [Accessed January, 4 2019]

Sugiyono. (2015). Metodologi Penelitian Kuantitatif, Kualitatif, dan R\&D. Bandung: Alfabeta

Wiratama, R. (2017). Penggunaan Boneka Tangan dalam Peningkatan Perilaku Mencuci Tangan pada Anak Code Utara Yogyakarta. http://eprints.poltekkesjogja.ac.id/48/ [Accessed January, 2 2019]

Eprilia, L, Fatimah, S, Koryati, D. (2018). Perbandingan Pengaruh Strategi Pembelajaran Index Card Match Dengan Giving Questions And Getting Answers Terhadap Hasil Belajar Peserta Didik Pada Mata Pelajaran Ekonomi Di Sma Negeri 3 Tanjung Raja. https://ejournal.unsri.ac.id/index.php/jp/article/view/5634 [Accessed January, 4 2019]

Ahmad, Arsita. (2018). Pengaruh Pendidikan Kesehatan Dengan Metode Bermain Puzzle Terhadap Kemampuan Mencuci Tangan Anak Tunagrahita Di Slb Negeri I Gowa. http://repositori.uinalauddin.ac.id/13302/1/Asrita\%20Ahmad 70300114032.pdf [Accessed March, 30 2019] 
Sarinarulita, Nawawi, E, Ibrahim, AR. (2014). Penerapan Model Pembelajaran Index Card Match Untuk Meningkatkan Keaktifan Dan Hasil Belajar Kimia Siswa Kelas X SMA. https://ejournal.unsri.ac.id/index.php/jurpenkim/article/download/2388/1261 [Accessed January, 14 2019]

Sholichah, M I. (2018) Teknik Modelling Dalam Meningkatkan Pembelajaran Bina Diri Pada Seorang Anak Tunagrahita Dwon Syndrom Di Slb-Ac Dharma Wanita Kecamatan Sidoarjo. http://digilib.uinsby.ac.id/26493/6/Iis\%20Maftuchatus\%20Sholichah_B93214103.pdf [Accessed March, 30 2019]

\section{PROFIL SINGKAT}

Peneliti utama pada penelitian ini adalah Umi Rofiatun Rojabtiyah, lahir di Temanggung tanggal 9 November 1997, mahasiswa Prodi DIV Keperawatan Magelang Poltekkes Kemenkes Semarang. Yang dibimbing oleh 3 dosen aktif di Prodi DIV Keperawatan Magelang Poltekkes Kemenkes Semarang yaitu Pramono Giri K, S.Pd, M.PH, Erna Erawati, S.Kep, Ns, M.Kep, dan Sunarko, S.Pd, M.Med.Ed. 